http://dx.doi.org/10.30681/23588403v11i01123139

\title{
RELAÇÕES ENTRE LINGUAGENS E DISCURSOS NUMA PRÁTICA PEDAGÓGICA
}

\author{
Data de recebimento: $30 / 10 / 2017$ \\ Aceite: 02/01/2018 \\ Karine Tiepo da SILVA (UPF) ${ }^{1}$ \\ Luciana M. CRESTANI (UPF) ${ }^{2}$
}

Resumo: Este artigo apresenta o desenvolvimento de uma prática pedagógica em que se exploram, ao mesmo tempo, a multiplicidade de linguagens implicadas na construção de sentidos e as relações dialógicas constitutivas dos textos. Os gêneros textuais utilizados para o desenvolvimento das atividades foram um poema, uma charge e uma história em quadrinhos (HQ). A revisão teórica que fundamenta a prática tem como base, principalmente, estudos de Bakhtin (2016) e de Fiorin (2006). A prática foi aplicada a uma turma de $1^{\circ}$ ano do Ensino Médio de uma escola da rede estadual situada na região Noroeste do RS e trouxe resultados positivos, o que justifica o interesse em compartilhá-la em forma de artigo.

Palavras-chave: Gêneros textuais. Relações dialógicas. Linguagens verbal e não verbal. Prática pedagógica.

Abstract: This article presents the development of a pedagogical practice in which we explore, at the same time, the multiplicity of languages involved in the construction of senses and dialogical relations constitutive of the texts. The texts genres used to develop the activities were a poem, a charge and a comic book. The proposal is based mainly on studies of Bakhtin (2016) and Fiorin (2006). The practice was applied to a group of first year of high school of a state school, located in the Northwest of the Rio Grande do Sul, and brought positive results, which justifies the interest in sharing it in the form of article.

Keywords: Text genres. Dialogic relationships. Verbal and non verbal languages. Pedagogical practice.

\section{Considerações iniciais}

O desempenho em leitura dos nossos estudantes ainda deixa a desejar, como apontam os instrumentos de avaliação do ensino instituídos pelo Ministério da Educação - a exemplo da Prova Brasil e do Exame Nacional do Ensino Médio (ENEM). A cada início de ano,

\footnotetext{
${ }^{1}$ Mestranda em Letras/2017 - Leitura e Formação do Leitor - UPF; Professora da rede Municipal e Estadual em São João da Urtiga - RS. E-mail: ktiepo@ gmail.com.br.

${ }^{2}$ Doutora em Letras. Professora no Curso de Letras e no Programa de Pós-graduação em Letras da Universidade de Passo Fundo - RS (UPF). E-mail: lucianacrestani@upf.br
} 
quando divulgados os resultados desses exames, reitera-se o discurso de que as médias projetadas pelo Índice de Desenvolvimento da Educação Básica (IDEB) não são atingidas ${ }^{3}$.

Os resultados são inquietantes porque demonstram um descompasso entre o que a escola ensina - ou privilegia - e o que consiste como objeto de conhecimento avaliado nessas provas. Basta uma olhada nesses instrumentos de avaliação para perceber que o foco recai sobre a interpretação e a capacidade de inter-relacionar ideias veiculadas por textos de diferentes gêneros, constituídos por diferentes linguagens. $\mathrm{E}$ isso não acontece só na prova objetiva, como também na de redação, em que se apresentam diferentes textos (ou excertos de textos) de gêneros variados sobre o tema, sendo necessário inter-relação e abstração das ideias ali expostas e habilidade discursiva e linguística para produzir um novo texto sobre elas. A propósito, os descritores da Prova Brasil e a matriz do ENEM de Linguagens, códigos e suas tecnologias explicitam as habilidades/competências avaliadas nessas provas e, portanto, tais instrumentos podem servir como norteadores das atividades em sala de aula.

Tendo isso em conta, como professores, é preciso que repensemos as práticas de ensino de língua materna, no sentido de desenvolver atividades que sigam na linha apontada pelos instrumentos de avaliação, não apenas para que se elevem os índices de desempenho dos alunos, mas para que efetivamente se promova o desenvolvimento das competências discursivas dos alunos. É nesse viés que se insere a proposta relatada neste artigo. Por meio dela, buscamos explorar, ao mesmo tempo, a multiplicidade de linguagens implicadas na construção de sentidos e as relações dialógicas constitutivas dos textos/enunciados. Tal proposta foi aplicada a uma turma de $1^{\circ}$ ano do Ensino Médio, de uma escola da rede estadual situada na região Noroeste do RS. Para desenvolvimento das atividades, utilizamos três textos de gêneros diferentes: uma charge, uma história em quadrinhos (HQ) e o poema "No meio do caminho", de Drummond. Este último tomado como texto-fonte com o qual os outros dois dialogam.

As bases teóricas que fundamentam a prática são, principalmente, os estudos de Bakhtin (2016), de Fiorin (2006) e de Lúcia Teixeira, Karla Faria e Silvia Souza (2014). O artigo está assim estruturado: inicialmente, apresentamos concepções teóricas que embasam a

\footnotetext{
${ }^{3}$ Conforme o portal do INEP (2016), na Prova Brasil de 2015 "as proficiências médias em Língua Portuguesa melhoraram em todos os níveis de ensino de 2013 para 2015, embora uma parte expressiva dos alunos ainda esteja nos níveis mais baixos da Escala de Proficiência, principalmente no $9^{\circ}$ ano do Ensino Fundamental e no $3^{\circ}$ ano do Ensino Médio". Quanto o desempenho do ENEM, na edição de 2015, a média geral foi de 505,3 pontos na prova de Linguagens, códigos e suas tecnologias e o número de alunos que zerou na redação foi de 53.032. Em 2014, foram 529.373 os participantes que zeraram a redação, de acordo com dados da EBC Agência Brasil (2016).
} 
prática para, logo após, apresentar o desenvolvimento da proposta. Por fim, tecem-se as considerações finais.

\section{Gêneros textuais e ensino de língua materna}

Partindo do princípio de que o estudo da língua deve ser o texto (leitura, interpretação e produção), nesta seção exploramos aspectos conceituais sobre texto, gênero textual, tipo textual, tecendo relações entre tais conceitos e o ensino de língua materna com vistas à formação de um sujeito apto a interagir nas diversas situações de comunicação/interação.

Comecemos pelo conceito de texto. O texto é, segundo Fiorin (2012), um todo organizado de sentido composto por procedimentos linguísticos próprios e por relações com o que está fora dele (aspectos sócio-históricos). Fiorin (2016) explica que o texto nasce da união de um plano de conteúdo (da ordem do discurso) com um plano de expressão (da ordem da materialidade). Assim, um mesmo discurso pode ser materializado em textos constituídos por sistemas sígnicos diferentes. Por exemplo, a história narrada em um romance - via linguagem verbal - pode ser materializada também em forma de filme. Neste último, além da linguagem verbal, outros elementos não verbais (cores, sons, gestos, expressões faciais e corporais etc.) são utilizados para a construção do sentido. Tem-se, então, o mesmo conteúdo (discurso) materializado por diferentes formas de expressão implicadas na constituição de diferentes gêneros textuais.

Um outro exemplo para clarearmos a noção de discurso: o discurso da miséria e do sofrimento por ela infligido pode se materializar num romance, num filme, num editorial de jornal, numa fotografia - a exemplo das imagens de Sebastião Salgado ${ }^{4}$, entre outros gêneros. Assim, o discurso é social, é de todos e, ao mesmo tempo, de ninguém. Já o texto, enquanto materialização de um discurso, implica escolhas enunciativas atreladas à situação de enunciação que atribuem a ele (ao texto) um caráter de individualidade, de autoria, como explica Bakhtin (2003, p. 310), ao dizer que "cada texto (como enunciado) é algo individual, único e singular, e nisso reside o seu sentido (sua intenção em prol da qual foi criado)".

\footnotetext{
${ }^{4}$ Vejam-se as imagens da exposição de Sebastião Salgado “A fome em preto e branco”, disponível no site: http://obviousmag.org/archives/2010/08/a_fome_em_preto_e_branco_-_sebastiao_salgado.html
} 
Nesse sentido, entendemos os gêneros textuais como sendo formas materializadas/concretas dos gêneros discursivos estudados por Bakhtin. Conforme Bakhtin (2016), o gênero discursivo é um tipo relativamente estável de enunciado que reflete as condições específicas e as finalidades das esferas da atividade humana, que são quase infinitas e estão relacionadas com a utilização da língua. Bakhtin (2016, p. 11) complementa que estes enunciados "refletem as condições específicas e as finalidades de cada referido campo não só por seu conteúdo (temático) e pelo estilo da linguagem, ou seja, pela seleção dos recursos lexicais, fraseológicos e gramaticais da língua, mas, acima de tudo, por sua construção composicional."

Esses três elementos constituintes dos gêneros discursivos - conteúdo temático, estilo e construção composicional - serão mais estereotipados ou um tanto flexíveis dependendo das esferas de utilização da língua. O conteúdo temático, segundo Fiorin (2006), é um domínio de sentido de que se ocupa o gênero e não o assunto específico de um texto. A construção composicional consiste no modo como o texto está estruturado, organizado. O estilo diz respeito à seleção de meios linguísticos (FIORIN, 2006).

Dependendo da situação de enunciação, escolhe-se o que será dito e como o será, ou seja, define-se qual o gênero mais adequado para os objetivos de tal comunicação implicadas aí todas as escolhas de ordem estrutural, temática e estilística relacionadas ao gênero. Conforme Bakhtin (2016, p.39),

nós aprendemos a moldar o nosso discurso em formas de gênero e, quando ouvimos o discurso alheio, já adivinhamos o seu gênero pelas primeiras palavras, adivinhamos um determinado volume (isto é, uma extensão aproximada do conjunto do discurso), uma determinada construção composicional, prevemos o fim, isto é, desde o início temos a sensação do conjunto do discurso que, em seguida, apenas se diferencia no processo da fala. Se os gêneros do discurso não existissem e nós não os dominássemos, se tivéssemos que criá-los pela primeira vez no processo do discurso, de construir livremente e pela primeira vez cada enunciado, a comunicação discursiva seria quase impossível.

Nessa esteira, Marcuschi (2008) argumenta que é impossível se comunicar verbalmente a não ser por algum gênero textual, assim como é impossível se comunicar 
verbalmente a não ser por algum texto. E acrescenta que isso acontece porque "toda a manifestação verbal se dá sempre por meio de textos realizados em algum gênero. Em outros termos, a comunicação verbal só é possível por algum gênero textual.” (2008, p. 154).

Vários fatores socioculturais ajudam a identificar os gêneros, assim como a definir que tipo de gênero deve ser usado no momento mais adequado à situação, seja na oralidade, seja na escrita. Esta capacidade de reconhecer e produzir essas marcas textuais chama-se "competência sociocomunicativa" (BRASIL, 2008), exercitada no contato com textos no dia a dia. O nível de linguagem, o jogo entre conteúdos explícitos e implícitos, o respeito às relações de interlocução tornam um texto adequado ou não a sua situação de produção/leitura. Essas características definem o uso de determinado gênero. Assim, é impossível desvincular o gênero textual da situação em que é utilizado o texto.

É importante, também, não confundir gênero textual com tipo textual. Marcuschi (2007) afirma que os gêneros textuais são inumeráveis, uma vez que, na dinamicidade das interações sociais, surgem novos gêneros ou se "remodelam" os antigos em novas versões 5 , adaptando-se aos novos suportes que os acomodam. Alguns exemplos de gêneros textuais: carta, bilhete, e-mail, artigo científico, artigo de opinião, entrevistas, discurso, poema, piada, horóscopo, recita médica, charge etc. Já os tipos textuais aparecem em número limitado: acrescenta que a expressão tipo textual designa

uma espécie de construção teórica definida pela natureza linguística de sua composição (aspectos lexicais, sintáticos, tempos verbais, relações lógicas). Em geral, os tipos textuais abrangem cerca de meia dúzia de categorias conhecidas como: narração, argumentação, exposição, descrição, injunção. (MARCUSCHI, 2007, p.27).

Grosso modo, a narração consiste no relato de um acontecimento, implicando a presença de personagens, tempo e espaço dos acontecimentos. A argumentação consiste em defender um determinado ponto de vista. A exposição se limita a apresentar uma determinada situação. Nos textos descritivos existe a riqueza de detalhes e a constante presença de adjetivos. Os textos injuntivos indicam procedimentos a serem realizados, motivo pelo qual,

${ }^{5}$ Como o blog, uma versão digital do diário impresso, e o chat, uma versão eletrônica da conversa face a face. 
geralmente, apresentam verbos no imperativo. É preciso lembrar, no entanto, que diferentes tipologias costumam aparecer na composição de um mesmo gênero textual ${ }^{6}$.

Kleiman (2005, p. 29) acrescenta que para participar de práticas discursivas sociais de forma exitosa, é necessário muito mais do que utilizar o alfabeto e localizar respostas e perguntas feitas sobre o texto, uma vez que nele estão envolvidos conhecimentos sobre "o que procurar nos textos, como funcionam, a quem estão dirigidos, quais são seus objetivos, como falar sobre eles, como disseminá-los, quais as relações que devem ser estabelecidas entre tema, público, objetivos, enfim, variados aspectos da situação comunicativa.”

Dessa forma, o trabalho com textos é enriquecedor e essencial. É válido lembrar que cada vez mais, somos rodeados por textos de natureza não verbal e sincrética ${ }^{7}$. Basta olhar ao redor para percebermos a infinidade de códigos, imagens, cores, formas que produzem sentidos na vida em sociedade e que precisam ser lidos, compreendidos e utilizados. Pensemos nas placas de trânsito, nas cores dos semáforos, nos vários códigos (verbais e não verbais) implicados numa operação num caixa eletrônico, para obter um ticket num parquímetro, para envio de uma mensagem por whatsapp... É, pois, urgente que comecemos a explorar mais essas “outras” linguagens também na escola, seja porque as avaliações do ENEM caminham nessa direção, seja porque essas linguagens variadas estão implicadas nas práticas sociais. Na próxima seção, discorremos sobre textos sincréticos.

\subsection{Sincretismo de linguagens em HQs e charges}

Quando, num texto, há o emprego conjunto de elementos verbais e não verbais, ou seja, pertencentes a linguagens de diferentes naturezas, dizemos que se trata de um texto sincrético. Por exemplo, uma conversa face a face é um texto sincrético, uma vez que além da linguagem verbal (na forma oral, neste caso) utilizamos gestos, expressões faciais e corporais que convergem na construção de sentidos. Nas palavras de Teixeira, Faria e Souza (2014, p. 320), "serão definidos como sincréticos os textos cujo plano de expressão é caracterizado pela mobilização de múltiplas linguagens apreendidas na mesma enunciação.”

\footnotetext{
${ }^{6}$ Numa bula de medicamento, por exemplo, encontramos trechos descritivos (composição/ fórmula medicamentosa), injuntivos (modo de usar), expositivos (indicações, reações adversas etc.).

${ }^{7}$ Textos compostos por linguagem verbal e não-verbal. Na seção seguinte, retomamos esse conceito.
} 
A leitura e a interpretação de textos sincréticos em sala de aula trazem benefícios e incentivam o hábito de ler/escrever. Teixeira (2014, p. 333) adverte que

cada texto, entretanto, solicita do leitor um olhar particular. Se o texto é uma HQ, os elementos visuais são mais evidentes como condutores da narrativa. [...] Cada atividade de interpretação será diferente, referente ao formato, às linguagens em relação e às possibilidades de sentido dos diferentes objetos semióticos.

$\mathrm{Na}$ sala de aula, as histórias em quadrinhos, charges, propagandas etc., são recursos linguísticos que devem ser explorados, pois além de trabalhar a prática de leitura de texto, põe em prática a leitura de mundo e, na maioria das vezes, mediante intertextualidade. Dos muitos textos sincréticos que podemos explorar na sala de aula, neste artigo, interessam-nos, sobremaneira, as charges e as HQs, uma vez que são esses os textos escolhidos para a prática com os alunos.

As HQs consistem em narrativas contadas por meio de outros recursos que não apenas a linguagem verbal. São, portanto, textos sincréticos, em que diferentes semioses (cores, escrita, figuras, símbolos, balões etc.) se unem para construção do sentido. Teixeira, Faria e Souza (2014, p. 324) dizem que "a leitura desse tipo de texto pressupões do leitor uma competência para apreender e relacionar a sequência construída pelos conteúdos verbais contidos nos balões de fala ou comentários do narrador com os conteúdos apresentados visualmente.” Para as autoras (2014, p. 326), as HQs

são ricas para análise, porque possibilitam, com economia de recursos, a compreensão de um fio narrativo. Além disso, operam com riqueza os procedimentos de expressão. Não podem configurar apenas como ilustração de algum conteúdo, devendo ser exploradas em toda a sua potencialidade de geração de sentidos. Analisar uma tira pode render não só a compreensão do emprego de categorias da expressão visual, mas também a produção escrita de textos narrativos, a formatação de diálogos, e ainda a apresentação dramatizada de uma história.

Portanto, podem-se explorar estes pequenos textos sincréticos como é feito com qualquer gênero, com atividades de leitura, interpretação, produção textual e aspectos gramaticais, atentando-se para recursos diversos do funcionamento desses gêneros. Pode-se 
dizer, também, que os textos sincréticos fazem parte de um mundo de leitura que desperta no aluno sua curiosidade e atualiza-se a cada momento. Ela requer gestos de interpretação diferentes para compreender sentidos implicados nas expressões faciais e corporais dos personagens, nos tipos de letras e pontuações, nas onomatopeias, nas cores ou tons (mais ou menos escuros), nos recursos utilizados (como os traços que definem os tipos de balões: pontilhados, pontiagudos, arredondados etc.). Enfim, há uma variedade de aspectos que podem ser explorados/ensinados aos alunos na leitura de textos dessa natureza.

De forma semelhante, a charge é também um texto de natureza sincrética e os recursos empregados são análogos aos das HQs (balões, imagens, cores, símbolos). Diferente dos quadrinhos, porém, a charge é "via de regra constituído por um quadro único" (FLÔRES, 2002, p.11). É um texto corrente em jornais diários, onde aparecem com intuito de satirizar e/ou criticar de forma bem-humorada algum acontecimento de ordem social veiculado no próprio jornal e em outros meios de comunicação. Assim, a compreensão da charge - e da crítica e humor implícitos - depende do conhecimento de outros textos/discursos sobre o acontecimento $^{8}$. É no entrecruzamento de textos/discursos que emerge, para o leitor, o sentido da charge. Tratemos, então, das relações dialógicas implicadas nos textos.

\section{Relações dialógicas: interdiscurso e intertexto}

A relação entre textos está presente do dia-a-dia das pessoas, pois é da natureza do discurso ser dialógico e responsivo. Conforme Bakhtin (2016), cada vez que se produz um enunciado o que se está fazendo é participando do diálogo com outros discursos. Cada enunciado é uma resposta a outros já ditos e, ao mesmo tempo, suscita novas e futuras respostas.

As relações dialógicas, no entanto, podem vir "marcadas" na materialidade do texto, ou não. Nesse sentido, Fiorin (2006) diferencia intertextualidade de interdiscursividade. Segundo o autor, a interdiscursividade é sinônimo de dialogismo, no sentido proposto por Bakhtin (2016), referindo-se ao diálogo implícito de um texto/discurso com outros textos/discursos que abordam o mesmo assunto - numa infinita cadeia responsiva - sem,

\footnotetext{
${ }^{8}$ Para Flôres (2002, p.14), a compreensão da charge requer "consideração do interdiscurso que se faz presente como memória, dando uma orientação ao sentido num contexto dado - aquele e não outro qualquer". 
necessariamente, citar uns aos outros. A interdiscursividade é uma característica intrínseca de todos os textos/discursos.

Já intertextualidade, para Fiorin (2006), implica a presença explícita de parte de um texto em outro, ou de aspectos materiais que remetam, diretamente, a um texto em específico. A intertextualidade se dá, por exemplo, quando ocorre a citação de autores e trechos de uma obra em outra, como acontece nos estudos científicos, trabalhos acadêmicos. Também a estilização e a paródia são formas de intertextualidade, uma vez que trazem em si marcas específicas que remetem ao texto-fonte. Assim, Fiorin (2006, p.52) postula que devemos chamar de intertextualidade "apenas as relações dialógicas materializadas em textos. Isso pressupõe que toda intertextualidade implica a existência de uma interdiscursividade (relação entre enunciados), mas nem toda interdiscursividade implica uma intertextualidade.”

A intertextualidade, porém, nem sempre é apreendida pelo leitor, uma vez que ela está relacionada ao "conhecimento de mundo" (KLEIMAN, 2010) do sujeito. Quando se exige do interlocutor uma busca na memória para a identificação do texto-fonte ao qual o texto remete e esta identificação não é processada, a construção do sentido fica prejudicada. Entretanto não é apenas isso que prejudica o entendimento. Muitas vezes o aluno não sabe o que olhar no texto para apreensão dos sentidos. A não percepção de elementos significativos para construção do sentido implica falha na interpretação. Por isso, é preciso ensinar os alunos a perceberem marcas que remetem ao essencial do texto e que estabelecem essas relações dialógicas. Essas marcas, nos textos sincréticos, não se encontram apenas no texto verbal, mas também nos elementos não verbais (cores, formas, traços, expressões, símbolos etc.). $\mathrm{O}$ dialogismo se dá em textos de diferentes gêneros, construídos por diferentes semioses.

Em se tratando de trabalho com gêneros textuais, destacamos a importância de explorar com os alunos não só a questão dos outros textos a que um enunciado se refere, mas também onde circulam esses textos, o ponto de vista defendido neles, as estratégias implicadas na defesa de pontos de vista, as convergências e divergências temáticas, os sentidos produzidos por elementos de diferentes linguagens, como já apontado na seção anterior... daí a complexidade e a riqueza de uma análise "intertextual".

Para o trabalho com intertextualidade, alguns elementos do texto precisam ser "reconhecidos" pelos enunciatários a fim de que a leitura realmente seja processada. Disso resulta a opção que adotamos de explorar, primeiramente, o texto-fonte, no intuito de que, depois, os alunos consigam estabelecer relação dos textos lidos com ele. Passamos, a seguir, ao relato da prática desenvolvida. 


\section{Da prática pedagógica desenvolvida com os alunos}

A prática proposta contempla a abordagem de um poema (texto-fonte), de natureza verbal, uma charge e uma HQ, ambas de natureza sincrética. Para a escolha dos textos, privilegiamos diferentes gêneros que apresentassem relações dialógicas e fossem constituídos por diferentes linguagens. A prática foi desenvolvida com uma turma de $1^{\circ}$ ano do ensino médio, composta por 23 alunos, de uma escola estadual do Noroeste do RS.

De acordo com Kleiman (2005, p. 35), a leitura exige "a ativação dos conhecimentos relativos ao gênero e à prática discursiva em que esse gênero funciona, ao assunto, aos textos e aos processos de textualização." Na mesma esteira, Lopes-Rossi (2011, p.76) defende que o trabalho com os gêneros discursivos não pode se basear apenas em algumas perguntas sobre o texto lido, e sim, o professor deverá organizar uma sequência de atividades como a

seleção de determinada quantidade de textos do gênero a ser estudado; distribuição desses textos aos alunos; levantamento do conhecimento prévio dos alunos sobre esse gênero; comentários sobre os aspectos discursivos do gênero; atividades para observação de seus aspectos temáticos e composicionais; opcionalmente, pesquisa dos próprios alunos para obtenção de outros exemplos; síntese dos aspectos observados.

Dessa forma, primeiramente, trabalhamos com o texto-fonte, o poema "No meio do caminho", de Drummond, para, a seguir, abordarmos a charge e a HQ, respectivamente. Para introduzir o trabalho com o poema, foram apresentados, em forma de slides, alguns poemas (de diversos autores), para que os alunos identificassem o gênero e, em uma conversa informal, pudessem perceber características desse gênero - temáticas variadas, estruturas diferenciadas, presença ou ausência de rimas, jogos de linguagem, sonoridade. Após este primeiro momento, foi feita uma exposição dialogada com explicações acerca deste gênero para aprofundamento quanto à função social, elementos que compõe o poema, linguagem, diferenças entre prosa e verso e poema e poesia. Em seguida, solicitou-se aos alunos uma pesquisa na internet acerca de informações gerais sobre o poeta Drummond (que ano 
nasceu/morreu, que contexto social e histórico viveu, produções, principais características de seu estilo poético). Após essa tarefa, os alunos tiveram contato com o poema de Drummond:

No meio do caminho9

No meio do caminho tinha uma pedra

Tinha uma pedra no meio do caminho

No meio do caminho tinha uma pedra

Nunca me esquecerei desse acontecimento

$\mathrm{Na}$ vida de minhas retinas tão fatigadas

Nunca me esquecerei que no meio do caminho

Tinha uma pedra

Tinha uma pedra no meio do caminho

No meio do caminho tinha uma pedra.

Carlos Drummond de Andrade.

Aguiar (2004, p. 19) afirma que ao ler um poema, o que há de concreto é o texto escrito, a mensagem do poeta, mas "ao nos adentrarmos em suas palavras, nos apossamos do sentimento que elas contêm e o que era invisível e comum na vida cotidiana assume nova dimensão e nos provoca, isto é, passamos a ver o mundo com outros olhos e a compreendê-lo mais atentamente." Daí a beleza dos poemas que, como outros textos de natureza estética, têm como objetivo o fazer-sentir e não o fazer-saber - a exemplo dos textos de natureza utilitária.

Nesta etapa, para a compreensão do texto, foram feitas, oralmente, algumas questões para explorar o sentido metafórico das palavras "pedra" e "caminho", em que este representa a vida e aquela simboliza desânimo, fraqueza, tristeza, problemas. A esse respeito, atentamos para o caráter atemporal e generalizante desse texto, desencadeado pelo uso de expressões metafóricas que podem ser atualizadas pelo leitor em qualquer tempo (mesmo num futuro distante) e aplicadas a diversas situações da vida diária. Além disso, exploramos a escolha da palavra "tinha" no lugar de "havia" e os efeitos de sentido decorrentes dessa escolha (informalidade, aproximação). Também levantamos questões sobre a constante repetição de "no meio do caminho tinha uma pedra", que traz sentido poético ao texto ao mesmo tempo em que reforça a proporção da dificuldade encontrada. Por fim, exploramos o significado das

${ }^{9}$ Este poema foi extraído do livro Alguma Poesia, 2013, p. 36. 
pedras no caminho. Em pequenos grupos, como forma de registro, os alunos produziram uma síntese dos aspectos observados sobre o poema.

Concluído esse processo inicial, partimos para a abordagem dos textos sincréticos, a charge e a HQ que dialogam com o poema de Drummond. Discini (2005, p.276) explica que, nas HQs, "o verbal colabora com o visual, para que se construam efeitos de sentido; no caso das HQS, o visual não só complementa o verbal, como predomina sobre ele.”. Contribuindo, Teixeira, Faria e Sousa (2014, p.324) afirmam que "a leitura desse tipo de texto pressupõe do leitor uma competência para apreender e relacionar a sequência construída pelos conteúdos verbais contidos nos balões de fala ou comentários do narrador com os conteúdos apresentados visualmente."

Nesse sentido, primeiramente, exploramos alguns aspectos concernentes aos gêneros charge e HQ para, depois, explorarmos as relações dialógicas que se estabelecem entre eles e o poema. Quanto aos gêneros, foram feitas reflexões sobre usos sociais desses textos, possíveis interlocutores, contexto de produção/circulação, finalidade, com destaque para as relações entre o texto verbal e as imagens que o acompanham, reconhecendo e avaliando as especificidades de leitura destes dois tipos de texto e confirmando a intencionalidade irônica da charge. Também foram apresentadas em multimídia algumas charges para serem interpretadas oralmente. Em seguida, foi exibida a charge abaixo:

Figura 1 - Charge

\section{TINHA UMA PEDRA NO} MEIO DO CAMINHO ...
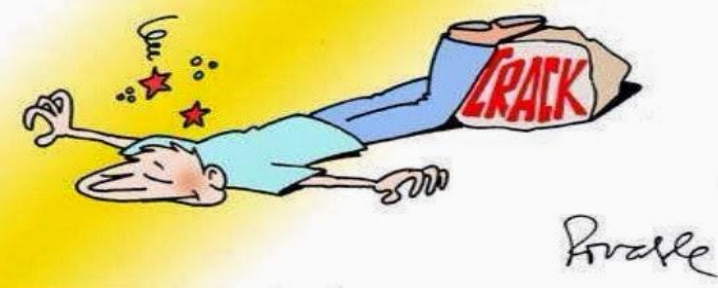
Almeida, 2017.

É oportuno aqui relembrar que, de acordo com Fiorin (2006), as relações interdiscursivas são concernentes à ordem do sentido, do discurso. Já as relações intertextuais são aquelas materializadas nos textos, que fazem referência, de modo explícito, a outro texto em específico, marcando-o no plano da expressão. Nesse sentido, esta charge dialoga tanto de forma interdiscursiva com o poema anterior, já que ambos falam de dificuldades da vida (metaforicamente representadas pela expressão "pedra no meio do caminho"), como de forma intertextual, já que está explícita a relação com o texto-fonte através da frase "Tinha uma pedra no meio do caminho...". Não nos detivemos, no entanto, em conceituar e diferenciar de forma pormenorizada essas relações aos alunos. Falamos, de forma mais abrangente, em "relações dialógicas".

Nessa lógica, para que a interpretação ocorresse, primeiramente foram feitas questões que possibilitassem a ativação do texto-fonte na memória dos alunos e instigassem a interpretação dos sentidos. Seguem as questões feitas: que elementos da charge nos permitem relacioná-la com o poema de Drummond? Qual o significado de "pedra" nessa charge? Há elementos no texto da charge que nos permitem dizer o que autor entende por "pedra" e, portanto, a que problema em específico o texto faz referência? E no poema, há elementos materiais que nos permitam depreender como tema a abordagem de um problema em específico? Qual a posição defendida pelo autor nessa charge? Que elementos verbais e não verbais the permitem dizer isso?

Novamente, em grupos, os alunos discutiram sobre as questões e formularam suas respostas, que foram, depois, comentadas no grande grupo. Terminada esta etapa, analisaram uma HQ do Garfield:

Figura 2 - HQ Garfield 

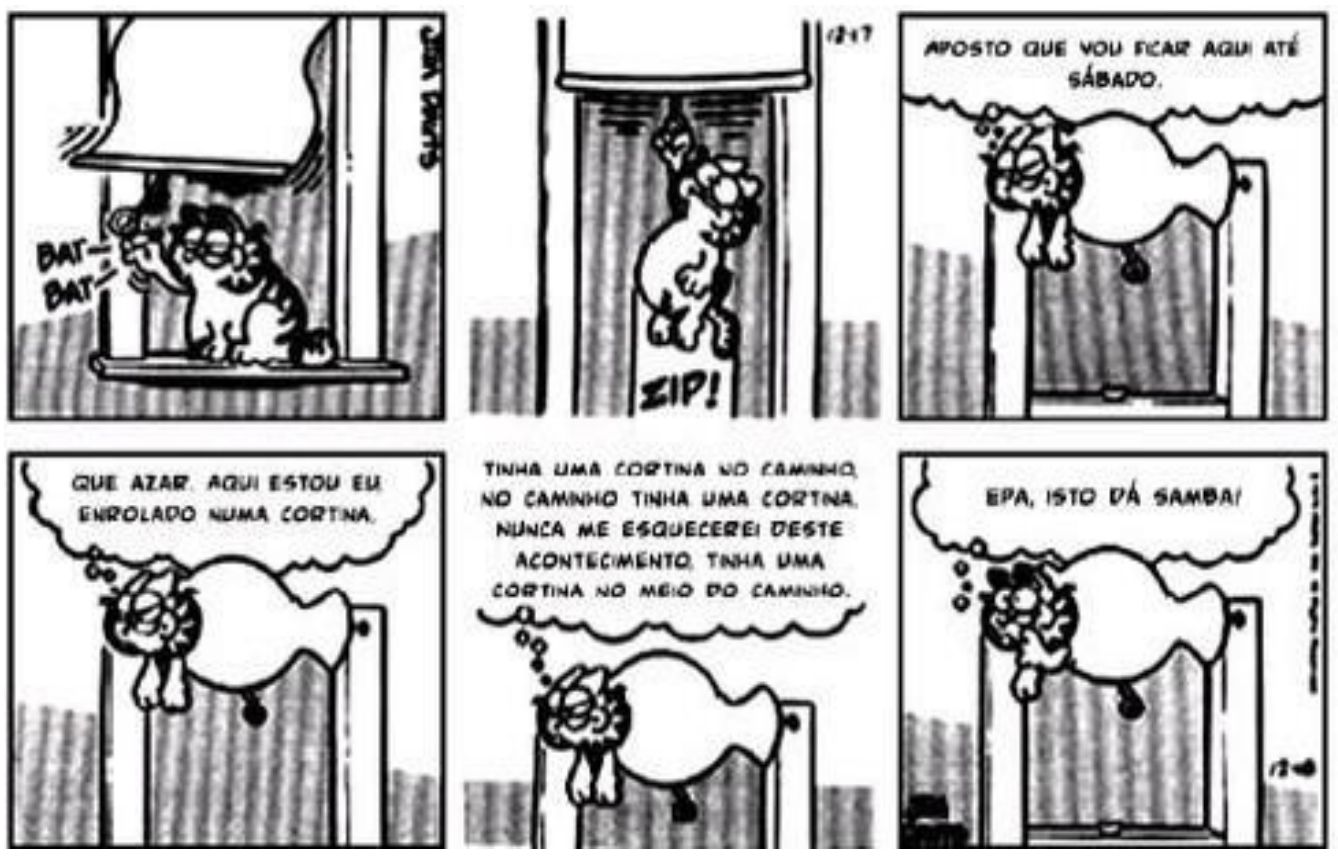

Davis, 2000.

Neste texto, tal como no anterior, aparecem marcas de intertextualidade (e de interdiscursividade, por óbvio) com o poema. A relação intertextual com o texto-fonte está explícita no enunciado do penúltimo quadrinho: "Tinha uma cortina no caminho, no caminho tinha uma cortina. Nunca me esquecerei deste acontecimento. Tinha uma cortina no meio do caminho", remetendo a trechos do poema de Drummond, com a adaptação do objeto gerador da dificuldade: da "pedra" para a "cortina". Como se trata de um texto sincrético, além do texto verbal, é preciso atentar aos objetos, às onomatopéias, expressões corporais e faciais do Garfield, traços/formas indicando movimento ( $2^{\circ}$ quadro) que constroem, em conjunto com a linguagem verbal, o sentido do texto.

Para a sequência da aula, propusemos as seguintes questões: conhecem algum texto semelhante? A palavra "cortina" pode ser tomada como um dos sentidos de "pedra", em Drummond? Que ideias implícitas o enunciado verbal do $3^{\circ}$ quadrinho traz? ${ }^{10}$ Que elementos verbais e não verbais nos permitem identificar a intenção do Garfield de abrir a cortina? As expressões faciais de Garfield não são idênticas em todos os quadrinhos. Quais os possíveis "estados emocionais" veiculados pelas expressões de Garfield nos quadros 1, 2, 3 e 6 ? Esse texto dialoga apenas com o poema de Drummond, ou também com a charge? Observando os

${ }^{10} \mathrm{O}$ intuito da questão era instigar inferências a partir do que foi dito. Os alunos deveriam perceber que o dia vivido na tirinha não era um sábado, e que este dia demoraria para chegar, o que vem marcado pela palavra "até" sábado. Possivelmente, os donos tivessem saído e só voltassem no sábado, por isso o gato ficaria preso ali. 
textos e pelo que já sabem sobre os gêneros charge e HQ, vocês poderiam mencionar algumas diferenças e semelhanças entre esses dois gêneros?

Também nesta etapa os alunos tomaram nota das questões e, em pequenos grupos, discutiram e elaboraram respostas que foram, depois, compartilhadas. Para encerrar o trabalho, sugerimos uma produção textual em grupos. A proposta foi de que produzissem um texto, em forma de um dos gêneros estudados, em que a "pedra no meio do caminho" representasse alguma dificuldade vivenciada ou relacionada com os estudos. Para ilustrar, apresentamos abaixo três produções selecionadas: um poema, uma charge e uma tirinha, que dialogam com o poema de Drummond.

Figura 3 - Poema produzido pelos alunos

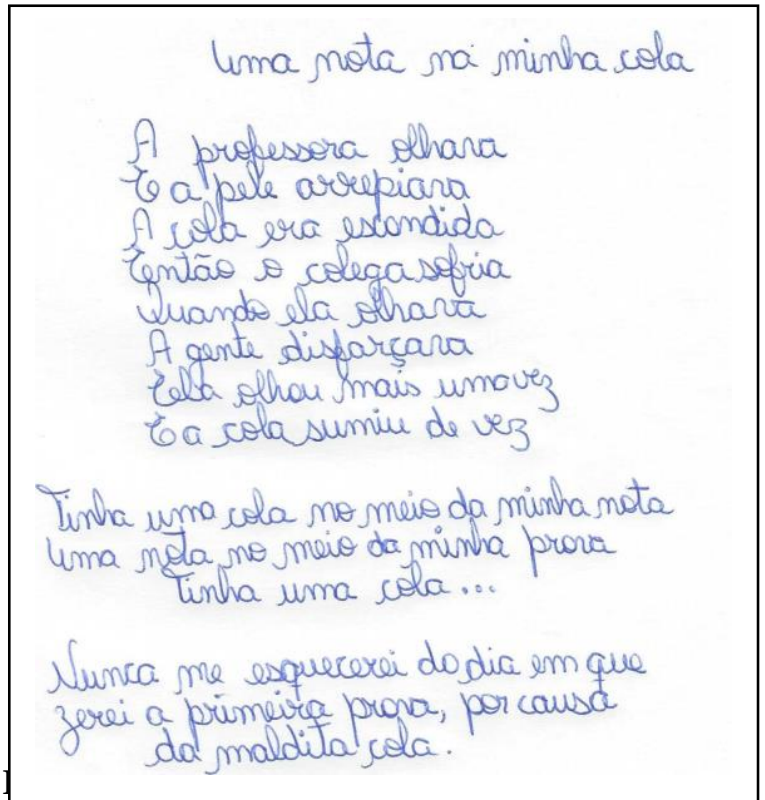

Figura 4 - Charge produzida pelos alunos

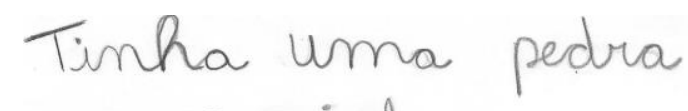
no caminho...

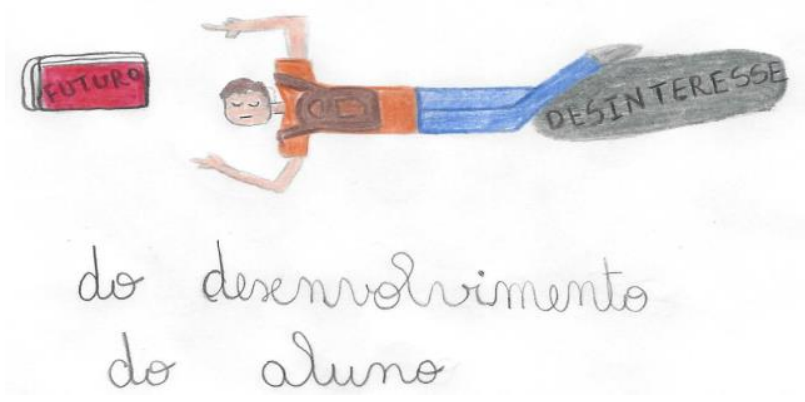

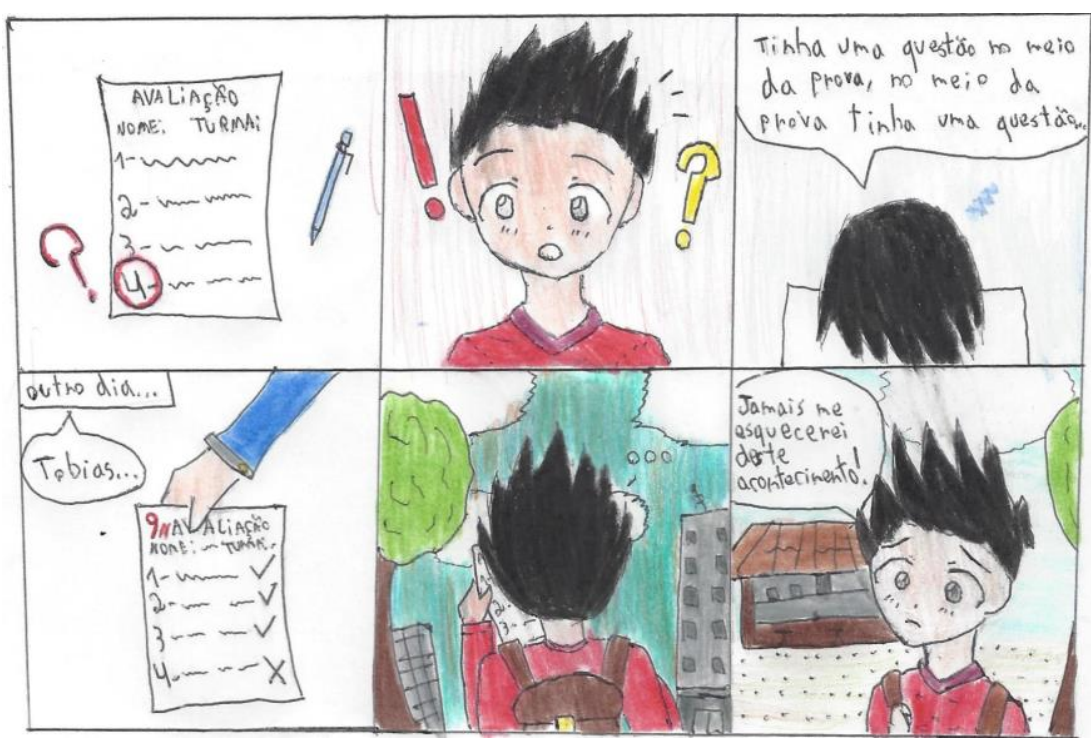




\section{Considerações Finais}

Após encerramento das atividades, que incluiu seminário para discussão dos resultados e formas de divulgação das produções, pudemos confirmar o que pressupúnhamos durante o planejamento da proposta: de que muitas "pedras" no caminho da interpretação deixariam de existir - ou, pelo menos, tomariam menores proporções - e, o principal, de que o aprendizado se daria de forma prazerosa.

Para concluir, queremos deixar claro que o intuito deste artigo não é, de forma alguma, fornecer uma "receita" para abordagem do dialogismo em sala de aula, mesmo porque temos consciência de que muitos outros aspectos poderiam ter sido explorados a partir dos textos abordados e dos temas implicados, assim como outros caminhos poderiam ter sido tomados para a abordagem e, quem sabe, levado a resultados até mais profícuos. O intuito é, sim, o de compartilhar uma experiência positiva que pode - numa atitude responsiva contribuir para o desenvolvimento de outras e novas propostas nessa perspectiva.

\section{Referências}

AGUIAR, V. T. de. O verbal e o não verbal. São Paulo: UNESP, 2004.

ANDRADE, C. D. de. Alguma Poesia. São Paulo: Companhia das Letras, 2013.

ALMEIDA, L. M. M. BLOG Os campeões não usam drogas. Disponível em: http://oscampeoesnaousamdrogas.blogspot.com.br/2013/11/uma-pedra-no-meio-docaminho.html. Acesso em: 15 jun. 2017.

BAKHTIN, M. Estética da criação verbal. 4.ed. São Paulo: Martins Fontes, 2003. Os gêneros do discurso. (Organização, tradução, posfácio e notas Paulo Bezerra). São Paulo: Editora 34, 2016.

BRASIL. Programa Gestão da Aprendizagem Escolar - Gestar II. Língua Portuguesa: Caderno de Teoria e Prática 3 - TP3: gêneros e tipos textuais. Brasília: Ministério da Educação, Secretaria de Educação Básica, 2008.

DAVIS, J. Garfield, um charme de gato - 7. Porto Alegre: L\&PM, 2000.

DISCINI, N. HQ e poema: diálogo entre textos. In: LOPES, I. C.; HERNANDES, N. (Orgs.). Semiótica: objetos e práticas. São Paulo: Contexto, 2005. p. 261-283. 
EBC AGÊNCIA BRASIL. Médias da provas do ENEM 2015 caem; desempenho individual sobe. Disponível em: < http://agenciabrasil.ebc.com.br/educacao/noticia/2016-01/enem-2015tem-queda-nas-medias-das-provas-desempenho-individual-sobe > . Acesso em 28 ago. 2017. FIORIN, J. L. Introdução ao pensamento de Bakhtin. São Paulo: Ática, 2006. Da necessidade da distinção entre texto e discurso. In: BRAIT, B.; SOUZA-ESILVA, M. C. (Orgs.). Texto ou discurso? São Paulo: Contexto, 2012, p. 145-165. FLÔRES, O. A leitura da charge. Canoas: Ed. ULBRA, 2002.

KLEIMAN, A. Texto e leitor: aspectos cognitivos da leitura. Campinas: Pontes, 2010. . Contribuições teóricas para o desenvolvimento do leitor: teorias de leitura e ensino. In: RÖSING, T. M. K.; BECKER, P. R. (Orgs.). Leitura e animação cultural: repensando a escola e a biblioteca. Passo Fundo: UPF, 2005, p. 21-41.

LOPES-ROSSI, M. A. G. Gêneros discursivos no ensino de leitura e produção de textos. In: KARWOSKI, A. M., GAYDECZKA, B.; BRITO, K. S. (Org.). Gêneros textuais: reflexões e ensino. São Paulo: Parábola Editorial, 2011, p. 69-82.

MARCUSCHI, L. A. Gêneros textuais: definição e funcionalidade. In: DIONÍSIO, A. MACHADO, A. R.; BEZERRA, M. A. (Orgs.). Gêneros textuais e ensino. 5. ed. Rio de Janeiro: Editora Lucerna, 2007, p. 19-36.

Produção textual, análise de gêneros e compreensão. 3. ed. São Paulo: Parábola Editorial, 2008.

PORTAL INEP. Inep apresenta resultados do Saeb/Prova Brasil 2015. Disponível em: <http://portal.inep.gov.br/artigo/-/asset_publisher/B4AQV9zFY7Bv/content/inep-apresentaresultados-do-saeb-prova-brasil-2015/21206. Acesso em 25 jul. 2017.

TEIXEIRA, L; FARIA, K.; SOUSA, S;. Textos multimodais na aula de português: metodologia de leitura. Revista Desenredo, v. 10, n. 2, 2014. Disponível em: http://seer.upf.br/index.php/rd/article/view/4295. Acesso em 12 ago. 2017. 